\title{
Effects of mother-child interaction on school adaptation of children according to maternal depression
}

Original article

\author{
Hanna Lee ${ }^{a}$, Jeong-Won Han ${ }^{\text {,** }}$ \\ ${ }^{a}$ Department of Nursing, Gangneung-Wonju National University, Gangwon-do 26403, Korea \\ ${ }^{b}$ College of Nursing Science, Kyunghee University, Seoul 1240, Korea
}

Received: 30 April 2020; Accepted: 11 June 2020; Published: 20 March 2021

\begin{abstract}
Objective: Factors influencing school adaptation of school-aged children include both executive function (EF) and parent-child interaction. This study aims to investigate the developmental trajectory of mother-child interaction longitudinally using latent growth model analysis. Methods: A longitudinal descriptive survey study was conducted. The participants comprised of 1,614 mothers and school-aged children, who participated in the Panel Study on Korean Children (6th-8th panel surveys). A model was designed and analyzed using latent growth modeling to estimate the pattern of change over time.

Results: In the group where the maternal depression was within the normal range, only the path by which the change rate of motherchild interaction affected school adaptation of children was statistically nonsignificant $(t=1.007, p=0.314)$. In the group where maternal depression was mild or higher, only the paths by which the initial value of mother-child interaction affected EF difficulty $(t=-2.75, p=0.032)$ and EF difficulty affected school adaptation $(t=-7.876, p<0.001)$ were statistically significant. Conclusions: This study confirms the research models developed by dividing mother-child interaction into two groups according to depression levels (i.e., normal range and mild or higher-level depression). The findings provide a basis for construction of individualized interventions.
\end{abstract}

Keywords: child $\bullet$ depression $\bullet$ interactions $\bullet$ school

(c) Shanxi Medical Periodical Press.

\section{Introduction}

As children spend most of their time at school, the socialization function of the family has been transferred to the school and children's school adaptation, which has become an important domain in relation to their social adaptation during adulthood. ${ }^{1}$ School adaptation is important for children, as it is used as a flexible coping resource for adapting to various human relationships and social life in adulthood. ${ }^{2}$ Additionally, since unsuccessful school adaptation can lead to dropping out from school and suicide during adolescence, and may lead to the development of family welfare and social problems that extend beyond personal problems, and therefore,

How to cite this article: Lee H, Han JW. Effects of mother-child interaction on school adaptation of children according to maternal depression. Front Nurs. 2021;1:33-42. 
school adaptation of school-aged children requires attention. ${ }^{1}$ Previous studies on school adaptation of schoolaged children have focused mainly on personal, family, and school factors. Specifically, gender, age, academic performance, and self-esteem have been reported as the personal factors affecting children's school adaptation, while family structure, communication with parents, parenting attitude, and family cohesion have been identified as the family factors. ${ }^{3-5}$

However, EF has recently been emphasized as a personal factor affecting school adaptation of school-aged children. EF is defined as the conscious cognitive processes that control goal-oriented thinking, behavior, and emotions in human beings, and as the thinking process used for solving various problems and performing adaptive behaviors in daily life and learning situations. ${ }^{6}$ EF generally consists of suppression, cognitive flexibility, and working memory. ${ }^{7}$ Suppression is the ability to intentionally control behaviors, thoughts, and responses that are automatically and predominantly performed. Cognitive flexibility is the ability to switch attention easily while performing tasks, to proficiently move between tasks and goals, and to process various data simultaneously. Working memory refers to the ability to continue tasks or ideas even while relevant information is being rapidly added and removed. EF continuously develops during childhood, which is a period of rapid growth, and is closely related to the development of the frontal lobe. As cognitive development continues until the beginning of adulthood, EF of school-aged children becomes an important factor that influences not only their school adaptation as children, but also their social adaptation as adults. ${ }^{8}$ Previous studies have reported that EF is strongly associated with academic performance; achievements related to reading, mathematics, and science; and self-regulation related to learning and school

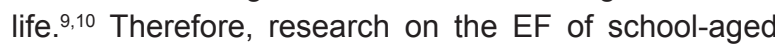
children is important to improve children's school adaptation by minimizing the learning, emotional, and behavioral problems because of EF disorders.

Along with the importance of EF, a personal factor, the importance of parent-child interaction as a family factor determining school adaptation of school-aged children has also been emphasized. ${ }^{11}$ Parent-child interaction is related to the development of the frontal lobe in children, since it supports their behavior and is a source of linguistic stimulation. Therefore, it is also a factor that increases children's EF. ${ }^{12,13}$ A previous study on twins ${ }^{12}$ considered the influence of parent-child interaction on children's EF and showed that children's self-regulation ability decreased when parents' sensitivity to interaction with children was low. Additionally, a study ${ }^{13}$ on toddlers showed that parental behavior and emotional tone appear to be especially influential on exuberant children's effortful control development.

Furthermore, the interaction between parents and children can be affected by parents' emotional problems. As parental depression has been reported to reduce the interaction between parents and children that influencing negatively children's EF, and hence interventions for parental depression are important to improve parent-child interaction. ${ }^{14-17}$ Specifically, the role of depression was explained in Barnard's mother-child interaction model, as the author contended that maternal traits and environmental characteristics influence the health and development of children when they interact with children's traits. ${ }^{18}$ In 2007, McGrath et al. ${ }^{19}$ also reported that maternal depression negatively influences mother-child interaction and this influence continues until children reach school age. Furthermore, in a prospective longitudinal study conducted in 2008, Pawlby et al. ${ }^{20}$ found that the incidence of school-aged children's mental health problems was four times higher when mothers had postpartum depression than when they did not. Thus, the importance of early intervention for mothers with depression is emphasized. It is also indicated that intervention for mother-child interaction must be approached according to the level of maternal depression.

However, depressive symptoms and motherchild interaction do not develop within a short period. Importantly, as the interactions from a child's birth onward influence his/her EF and school adaptation, it is important to approach and create interventions for mother-child interaction with a long-term rather than a short-term perspective..$^{21}$ Most studies have not considered the level of maternal depression nor comprehensively assessed mother-child interaction, EF, and school adaptation. Furthermore, they have only conducted cross-sectional investigations at one point rather than conducting longitudinal examinations. Therefore, even findings of a partial relationship are limited as basic data required for improving children's school adaptation. Eventually, research on children's school adaptation must comprehensively investigate the personal and family factors involved. In addition, the rate of longitudinal change in the interaction between parents and children must be determined and the effects of such a change on children's EF and school adaptation must be identified.

Therefore, this study determines the effect of mother-child interaction over time on school-aged children's school adaptation, treating EF difficulties of the children as a mediating factor. In addition, it attempts to provide basic data for the development of individualized intervention plans to improve school 
adaptation in school-aged children by using research models for investigating the two levels of maternal depression, a factor that especially affects motherchild interaction.

\section{Material and Methods}

\subsection{Study design}

This study is a longitudinal descriptive survey study conducted to determine the relationship between the developmental trajectory of mother-child interaction, children's EF difficulties, and school adaptation using the Panel Study on Korean Children.

\subsection{Participants}

The Panel Study on Korean Children (conducted by the Korea Institute of Child Care and Education) used in this study provided longitudinal survey data on neonates born in 2008 and their mothers and local community environment. The participants in this study were mothers aged 20 years or older and their children, who had participated in the 6th (2013) to the 8th (2015) panel surveys. The Panel Study on Korean Children targeted all households in which a baby was born between April and July 2008 at sampled medical institutions with 500 or more annual deliveries in 2006 was included in the sample and excluding those who declined to participate in the survey. In total, 2,562 households were willing to participate in the panel survey and they were recruited for the pilot sample and 2,150 households with a newborn baby were selected for the final sample. The sampling for the Panel Study on Korean Children was conducted using a stratified multi-stage sampling technique in which medical birthing institutions were selected in the first stage and the households with babies born at the selected medical institutions were selected as the pilot sample in the second stage. The final sample was drawn from the pilot sample households that were willing to participate in the panel survey in the third stage. The sample maintenance rate of the 2008 sample determined per the suggestion of the survey team of the Panel Study on Korean Children for the validity of the sample was $77.3 \%$ in the 6 th panel survey $(2013), 75.3 \%$ in the 7 th panel survey (2014), and $74.3 \%$ (2015) in the 8th panel survey (2015). The final participants in this study comprised of 1,614 mothers who participated in the 6th through the 8th panel surveys and the survey of mothers and their children. Previous studies ${ }^{14-17}$ of mothers and children have found correlations between the levels of depression of mothers and children, and found that the presence or absence of mother's depression affects children's behavior. Hence, for the present study, only those mothers whose depression was consistently at mild or higher levels or within the normal range for the previous three years of the 6th through the 8th survey periods were selected as participants.

\subsection{Measurement}

\subsubsection{Depression}

Depression was measured using an abbreviated instrument developed in 2002 by Kessler et al. ${ }^{22}$ for the U.S. National Health Interview Survey to assess the mental health of the public. The instrument consists of six items, each measured on a five-point Likert scale, with higher scores indicating higher levels of depression. Depression is classified as within the normal range (6-13 points), mild/moderate (14-18 points), or severe (19-30 points). In this study, depression level was classified into within the normal range, or mild or higher. The reliability of the instrument measured by Cronbach's $\alpha$ by Kessler et al. (2002) was 0.89 , and the equivalent figures obtained in this study for the 6th, 7th, and 8th panel surveys were $0.89,0.91$, and 0.90 , respectively.

\subsubsection{Mother-child interaction}

Mother-child interaction was measured using an instrument developed in the Early Childhood Longitudinal Study conducted by the National Center for Education Statistics, which is translated by the research team of the Panel Study on Korean Children, and tested for validity by the survey team of the Early Childhood Longitudinal Study. The instrument consists of nine items, each measured on a four-point Likert scale, with higher scores indicating higher levels of mother-child interaction. In this study, Cronbach's $\alpha$ for the 6th, 7th, and 8th panel surveys were found to be $0.84,0.83$, and 0.84 , respectively.

\subsubsection{EF difficulty}

EF difficulty was measured using an instrument developed by Song in $2014 .{ }^{23}$ The instrument consists of 40 items categorized in four sub-areas (planning-organizing difficulty, behavior control difficulty, emotional control difficulty, and attention-concentration difficulty). Each item is measured on a three-point Likert scale, with higher scores indicating higher levels of EF difficulty. The reliability of the instrument as measured by Cronbach's $\alpha$ by Song ${ }^{23}$ was 0.95 , and the value obtained in this study was 0.98 for the 8 th panel survey. 


\subsubsection{School adaptation}

School adaptation was measured using the school adaptation inventory developed by Chi and Jung in $2006^{24}$ for first-grade elementary school students. The inventory consists of 35 items categorized in four sub-areas (school adaptation, academic performance adjustment, peer adjustment, and teacher adaptation). Each item is measured on a five-point Likert scale, with higher scores indicating higher levels of school adaptation. The reliability of the inventory measured by Cronbach's $\alpha$ by Chi and Jung ${ }^{24}$ was 0.98 , and the value measured in this study was 0.96 for the 8 th panel survey.

\subsubsection{Ethical considerations}

\subsubsection{Data collection and analysis}

A research plan for obtaining required data was submitted to the Panel Study on Korean Children operated by the Korea Institute of Child Care and Education through its homepage and reviewed by the same. The panel study was conducted in accordance with the process of the Institutional Bioethics Committee of the Child Rearing Policy Institute. Data were collected from February 22 to March 10, 2018. The data received did not contain sensitive data from which personal information could be identified. Data analysis was carried out after applying the longitudinal weights recommended by the Panel Study on Korean Children. Further, descriptive statistics were computed using SPSS WIN 23.0 to identify the general characteristics of the participants. The reliability of the instruments used was assessed using Cronbach's $\alpha$. Skewness and kurtosis were obtained through data normality testing. It was determined whether their absolute values were less than 3 and 10, respectively, so that the Full Information Maximum Likelihood method-a parameter estimation method that accounts for missing data-could be used. ${ }^{25}$ In addition, the correlations between the variables were checked to determine their multicollinearity. Further, models were designed using latent growth modeling with AMOS 17.0 to estimate changing patterns in mother-child interaction over time. The significance of initial values and the rate of change were determined for the changing patterns in mother-child interaction over time and the final selection of the most appropriate model was made by comparing the goodness of fit of the no-change and linear-change models. The goodness of fit of the model was determined using chi-square $\left(\chi^{2}\right)$, the normed fit index $(N F I) \geq 0.90$, the relative fit index (RFI), the incremental fit index (IFI), the Tucker Lewis Index (TLI), the comparative fit index
$(\mathrm{CFI}) \geq 0.90$, and the root mean square error of approximation (RMSEA) $\leq 0.10 .{ }^{25}$ Also, the influence of the developmental trajectory of mother-child interaction on EF difficulty and school adaptation was determined by testing the significance of the path coefficients to identify the relationships between the variables. Finally, bootstrapping was performed to determine the mediating effect of EF difficulty between the developmental trajectory of mother-child interaction and school adaptation.

\section{Results}

\subsection{General participant characteristics}

Based on the results of the 8th survey of the Panel Study on Korean Children, the average maternal age was 37.89 years; 749 participants $(49.2 \%)$ had attained an educational level of a four-year college degree or higher, making it to the most prevalent education level in the sample; 720 participants (44.6\%) were employed or in school; 894 participants (55.4\%) were full-time homemakers; and the average monthly household income was KRW4.6299 million. The average age of the children was 80.0 months; 815 children (50.5\%) were male, and 799 children (49.5\%) were female.

\subsection{Correlations between factors and changes in each factor by time of mother-child interaction}

To determine the changing patterns of mother-child interaction over time and the level of children's EF difficulty and school adaptation, average values were calculated. Mother-child interaction tended to gradually decrease over time. Furthermore, the average scores for EF difficulty and school adaptation were 1.30 and 3.96 points, respectively. According to the results of the skewness and kurtosis, calculations performed to test the normality of each factor and, the normality assumption was satisfied as the absolute values of skewness and kurtosis were less than 3 and 10, respectively (Table 1). The correlations between the factors were all significant at the 0.05 level (Table 2).

\subsection{Test of construct validity by factor analysis}

Construct validity was tested for validation, as abstract constructs are frequently used in research models for structural equation models. To determine construct validity, confirmatory factor analysis was performed to test the convergent validity and discriminant validity as 


\begin{tabular}{|c|c|c|c|c|c|c|}
\hline Variables & M & SD & Skewness & SE & Kurtosis & SE \\
\hline Mother-child interaction 6th & 2.29 & 0.50 & 0.37 & 0.06 & 0.25 & 0.12 \\
\hline Mother-child interaction 7th & 2.25 & 0.50 & 0.56 & 0.06 & 0.76 & 0.12 \\
\hline Mother-child interaction 8th & 2.18 & 0.49 & 0.56 & 0.06 & 0.55 & 0.12 \\
\hline Executive function & 1.30 & 0.40 & 0.86 & 0.07 & 3.17 & 0.15 \\
\hline Subfactor1: Planning-organizing difficulties & 1.47 & 0.52 & 1.20 & 0.07 & 0.51 & 0.15 \\
\hline Subfactor 2: Behavior control difficulty & 1.28 & 0.44 & 2.01 & 0.07 & 3.60 & 0.15 \\
\hline Subfactor 3: Emotional control difficulty & 1.22 & 0.44 & 2.50 & 0.07 & 5.82 & 0.15 \\
\hline Subfactor 4: Attention-concentration difficulty & 1.25 & 0.44 & 2.18 & 0.07 & 4.33 & 0.15 \\
\hline School adjustment & 3.96 & 0.66 & -0.63 & 0.07 & 0.23 & 0.15 \\
\hline Subfactor 1: School life adjustment & 4.07 & 0.94 & -1.06 & 0.07 & 0.27 & 0.15 \\
\hline Subfactor 2: Academic performance adjustment & 3.82 & 0.85 & -0.61 & 0.07 & -0.04 & 0.15 \\
\hline Subfactor 3: Peer adjustment & 3.97 & 0.75 & -0.65 & 0.07 & 0.10 & 0.15 \\
\hline Subfactor 4: Teacher adjustment & 3.94 & 0.85 & -1.14 & 0.07 & 1.66 & 0.15 \\
\hline
\end{tabular}

Note: $M$, mean; SD, standard deviation; SE, standard error.

Table 1. Descriptive statistic of variables $(N=1614)$.

\begin{tabular}{|c|c|c|c|c|c|c|c|c|c|c|c|}
\hline Variables & $\mathrm{X}_{1}$ & $\times 2$ & X3 & $\mathrm{X} 4$ & $\times 5$ & X6 & $\times 7$ & $\mathrm{X} 8$ & X9 & $\mathrm{X} 10$ & $\mathrm{X} 11$ \\
\hline $\begin{array}{l}\text { X1: Mother-child } \\
\text { interaction 6th }\end{array}$ & 0.79 & & & & & & & & & & \\
\hline $\begin{array}{l}\text { X2: Mother-child } \\
\text { interaction 7th }\end{array}$ & $0.59^{\star}$ & 0.78 & & & & & & & & & \\
\hline $\begin{array}{l}\text { X3: Mother-child } \\
\text { interaction 8th }\end{array}$ & $0.53^{*}$ & $0.56^{*}$ & 0.80 & & & & & & & & \\
\hline $\begin{array}{l}\text { X4: Planning-organizing } \\
\text { difficulties }\end{array}$ & $-0.43^{\star}$ & $-0.35^{\star}$ & $-0.21^{\star}$ & 0.91 & & & & & & & \\
\hline $\begin{array}{l}\text { X5: Behavior control } \\
\text { difficulty }\end{array}$ & $-0.36^{\star}$ & $-26^{\star}$ & $-0.28^{\star}$ & $0.74^{*}$ & 0.95 & & & & & & \\
\hline $\begin{array}{l}\text { X6: Emotional control } \\
\text { difficulty }\end{array}$ & $-0.20^{\star}$ & $-22^{*}$ & $-0.22^{\star}$ & $0.49 *$ & $0.71 *$ & 0.94 & & & & & \\
\hline $\begin{array}{l}\text { X7: Attention- } \\
\text { concentration difficulty }\end{array}$ & $-0.30^{\star}$ & $-17^{\star}$ & $-0.31^{\star}$ & $0.71^{*}$ & $0.74^{*}$ & $0.51^{*}$ & 0.84 & & & & \\
\hline $\begin{array}{l}\text { X8: School life } \\
\text { adjustment }\end{array}$ & $0.41^{\star}$ & $0.23^{*}$ & $0.30 \star$ & $-0.65^{\star}$ & $-0.74^{\star}$ & $-0.54^{\star}$ & $-0.62^{\star}$ & 0.82 & & & \\
\hline $\begin{array}{l}\text { X9: Academic } \\
\text { performance adjustment }\end{array}$ & $0.38^{*}$ & $0.28^{*}$ & $0.32^{*}$ & $-0.66^{*}$ & $-0.47^{\star}$ & $-0.30 *$ & $-0.45^{\star}$ & $0.57^{\star}$ & 0.84 & & \\
\hline $\begin{array}{l}\text { X10: Peer } \\
\text { adjustment }\end{array}$ & $0.38^{\star}$ & $0.25^{*}$ & $0.37^{\star}$ & $-0.58^{\star}$ & $-0.57^{\star}$ & $-0.53^{\star}$ & $-0.46^{\star}$ & $0.63^{\star}$ & $0.73^{\star}$ & 0.83 & \\
\hline $\begin{array}{l}\text { X11: Teacher } \\
\text { adjustment }\end{array}$ & $0.37^{\star}$ & $0.29 *$ & $0.38^{*}$ & $-0.21^{\star}$ & $-0.14^{\star}$ & $-0.28^{\star}$ & $-0.36^{\star}$ & $0.20^{\star}$ & $0.44^{*}$ & $0.40^{\star}$ & 0.79 \\
\hline
\end{tabular}

Note: ${ }^{\star} p<0.05$

Shaded section: discriminant validity.

Non-shaded section: correlation.

Table 2. Correlations and changes in each factor by time.

a method of assessing whether constructs have been correctly measured. Maximum likelihood estimation was performed using AMOS 23.0 (SPSS Korea Data Solution Inc.) for the confirmatory factor analysis. During the convergent validity analysis, a total of four items (the first item in the 6th, 7th, and 8th surveys of mother-child interaction, "Read a book to the child," and the 11th item for school adaptation, "Behaves younger than age") were eliminated. Convergent validity was confirmed, as the average variance extracted (AVE) values were 0.62 to 0.91 , which were greater than the criteria of 0.50 , and the construct reliability values were 0.87 to 0.98 , which 
were greater than the criteria of 0.70 . Discriminant validity shows the difference between different latent variables. The $\sqrt{ }$ AVE values and correlation coefficients of the two constructs were compared. Discriminant validity was confirmed, as the $\sqrt{A V E}$ values of the latent variables were between 0.78 and 0.95 , which were greater than the correlation coefficients between the latent variables (Table 2).

\subsection{Estimation of the goodness of fit of the latent growth model and developmental trajectories of mother-child interaction}

The goodness of fit of the no-change and linear models was determined to test the statistical significance of the changing patterns of mother-child interaction according to the level of maternal depression, and to determine the best model for changing trends. According to the results, a linear model $\left(\chi^{2}=4.45, \mathrm{df}=3, \mathrm{NFI}=0.99, \mathrm{RFI}=0.99\right.$, $\mathrm{IFI}=0.99, \mathrm{TLI}=0.99, \mathrm{CFI}=0.99$, and $\mathrm{RMSEA}=0.01)$ is appropriate for the group of mothers whose depression is within the normal range. The hypothesis stating that the average initial value of mother-child interaction with 0 was rejected, as the initial value of the mother-child interaction was $2.30(p<0.001)$ and the individual difference in the initial value of the mother-child interaction was statistically significant. Mother-child interaction decreased as each year passed, with an average rate of change of $-0.11(p<0.001)$. The rate of change also demonstrated individual differences, with an average variance of $0.17(p<0.001)$. The correlation between the initial value of mother-child interaction and the rate of change was $-0.30(p<0.001)$, indicating that the higher the initial value of the mother-child interaction, the slower the reduction of the mother-child interaction level over time (Table 3 ).

Alinear model $\left(\chi^{2}=4.30, \mathrm{df}=3, \mathrm{NFI}=0.96, \mathrm{RFI}=0.94\right.$, $\mathrm{IFI}=0.98, \mathrm{TLI}=0.98, \mathrm{CFI}=0.99$, and $\mathrm{RMSEA}=0.03$ )

\begin{tabular}{llcc}
\hline $\begin{array}{l}\text { Level of } \\
\text { depression }\end{array}$ & Variables & Mean & Variance \\
\hline \hline Normal & Mother-child interaction Intercept & 2.30 & 0.16 \\
& Mother-child interaction Slope & -0.11 & 0.03 \\
& Mother-child interaction & $-0.30^{*}$ \\
& intercept-slope correlation & & \\
\hline Mild/ & Mother-child interaction Intercept & 2.14 & 0.23 \\
Moderate/ & Mother-child interaction Slope & -0.09 & 0.18 \\
Severe & Mother-child interaction & $-0.64 *$ \\
& Intercept-slope correlation & & \\
\hline
\end{tabular}

Note: ${ }^{\star} p<0.05$

Table 3. Trajectories of the variables. was also found to be appropriate for the group of mothers with mild or higher depression levels. The hypothesis stating that the average initial value of mother-child interaction with 0 was rejected, as the initial value of mother-child interaction was $2.14(p<0.001)$ and the individual difference in the initial value of the motherchild interaction was statistically significant. Motherchild interaction decreased as each year passed, with an average rate of change of $-0.09(p<0.001)$. The rate of change also demonstrated individual differences, with an average variance of $0.11(p<0.001)$. The correlation between the initial value of mother-child interaction and the rate of change was found to be $-0.64(p<0.001)$, indicating that the higher the initial value of the motherchild interaction, the slower the reduction of the motherchild interaction level over time (Table 3).

\subsection{Analysis of mother-child interaction, executive function difficulty, and school adaptation using a multivariate latent growth model}

The longitudinal relationship between mother-child interaction, EF difficulty, and school adaptation was tested by dividing the participants based on the depression level. One group included mothers having depression within the normal range and the other included mothers having mild or higher-level depression. The goodness of fit of the model for the normal-range maternal depression group was $\chi^{2}=5.76, \mathrm{df}=5, \mathrm{NFI}=0.99, \mathrm{RFI}=0.99$, IFI $=0.99, \mathrm{TLI}=0.99, \mathrm{CFI}=0.99$, and RMSEA $=0.01$. Furthermore, out of five paths, only the path by which the change rate of mother-child interaction affected school adaptation of school-aged children was statistically nonsignificant $(t=1.007, p=0.314)$. The goodness of fit of the model for the mild or higher-level maternal depression group was $\chi^{2}=7.15, \mathrm{df}=5, \mathrm{NFI}=0.96, \mathrm{RFI}=0.96$, $\mathrm{IFI}=0.98, \mathrm{TLI}=0.96, \mathrm{CFI}=0.98$, and RMSEA $=0.03$. Furthermore, out of five paths, only the paths by which the initial value of mother-child interaction influenced EF difficulty $(t=-2.75, p=0.032)$ and EF difficulty influenced school adaptation $(t=-7.876, p<0.001)$ were statistically significant (Table 4 ).

\section{Discussion}

This study identifies the changing patterns in motherchild interaction over time, using data from the 6th to the 8th surveys of the Panel Study on Korean Children, and longitudinally analyzes the relationship between EF difficulties and school adaptation of school-aged children. The results and the management implications of this study are described below. 


\begin{tabular}{|c|c|c|c|c|c|c|c|c|c|}
\hline $\begin{array}{l}\text { Level of } \\
\text { depression }\end{array}$ & $\begin{array}{l}\text { Exogenous } \\
\text { variables }\end{array}$ & & $\begin{array}{l}\text { Endogenous } \\
\text { variables }\end{array}$ & $\beta$ & $\mathrm{CR}$ & $p$ & $\begin{array}{c}\text { Direct } \\
\text { effects }(p)\end{array}$ & $\begin{array}{l}\text { Indirect } \\
\text { effects }(p)\end{array}$ & Total effects $(p)$ \\
\hline \multirow[t]{5}{*}{ Normal } & $\begin{array}{l}\text { Mother-child } \\
\text { interaction } \\
\text { intercept }\end{array}$ & $\rightarrow$ & $\begin{array}{l}\text { Executive } \\
\text { function }\end{array}$ & -12 & 2.47 & 0.038 & $-12(0.038)$ & & \\
\hline & $\begin{array}{l}\text { Mother-child } \\
\text { interaction Slope }\end{array}$ & $\rightarrow$ & $\begin{array}{l}\text { Executive } \\
\text { function }\end{array}$ & -20 & 2.62 & 0.040 & $-20(0.040)$ & & \\
\hline & $\begin{array}{l}\text { Mother-child } \\
\text { interaction } \\
\text { intercept }\end{array}$ & $\rightarrow$ & $\begin{array}{l}\text { School } \\
\text { adjustment }\end{array}$ & 0.25 & 3.67 & $<0.001$ & $0.25(<0.001)$ & $0.11(<0.001)$ & $0.36(<0.001)$ \\
\hline & $\begin{array}{l}\text { Mother-child } \\
\text { interaction slope }\end{array}$ & $\rightarrow$ & $\begin{array}{l}\text { School } \\
\text { adjustment }\end{array}$ & 0.27 & 1.01 & 0.314 & $0.27(0.314)$ & $0.14(<0.001)$ & $0.41(0.047)$ \\
\hline & Executive function & $\rightarrow$ & $\begin{array}{l}\text { School } \\
\text { adjustment }\end{array}$ & -0.67 & -24.15 & $<0.001$ & $-0.67(<0.001)$ & & \\
\hline \multirow[t]{5}{*}{$\begin{array}{l}\text { Mild/ } \\
\text { Moderate/ } \\
\text { Severe }\end{array}$} & $\begin{array}{l}\text { Mother-child } \\
\text { interaction } \\
\text { intercept }\end{array}$ & $\rightarrow$ & $\begin{array}{l}\text { Executive } \\
\text { function }\end{array}$ & -0.35 & -2.75 & 0.032 & $-0.35(.032)$ & & $-0.35(0.032)$ \\
\hline & $\begin{array}{l}\text { Mother-child } \\
\text { interaction slope }\end{array}$ & $\rightarrow$ & $\begin{array}{l}\text { Executive } \\
\text { function }\end{array}$ & -0.27 & 0.95 & 0.338 & $-0.27(0.338)$ & & $-0.27(0.338)$ \\
\hline & $\begin{array}{l}\text { Mother-child } \\
\text { interaction } \\
\text { intercept }\end{array}$ & $\rightarrow$ & $\begin{array}{l}\text { School } \\
\text { adjustment }\end{array}$ & 0.15 & 1.08 & 0.276 & $0.15(0.276)$ & $0.26(<0.001)$ & $0.41(0.032)$ \\
\hline & $\begin{array}{l}\text { Mother-child } \\
\text { interaction slope }\end{array}$ & $\rightarrow$ & $\begin{array}{l}\text { School } \\
\text { adjustment }\end{array}$ & 0.17 & 0.94 & 0.344 & $0.17(0.344)$ & $0.17(0.320)$ & $0.34(0.355)$ \\
\hline & Executive function & $\rightarrow$ & $\begin{array}{l}\text { School } \\
\text { adjustment }\end{array}$ & -0.25 & -7.87 & $<0.001$ & $-0.55(<0.001)$ & & $-0.55(<0.001)$ \\
\hline
\end{tabular}

Note: $\beta$, standardized regression weights; $\mathrm{CR}$, critical ratio.

Table 4. Effects of predictive variables on endogenous variables in the model.

First, mother-child interaction tended to decrease over time for both the groups (normal range maternal depression and mild or higher-level maternal depression). Furthermore, significant individual differences were found. It means that the mother-child interaction over time does not change in the same pattern for everyone, but in various patterns depending on the individual. The decreasing trends found are similar to the findings of Hallers-Haalboom et al.' ${ }^{26}$ study in 2017 which investigated childcare sensitivity according to the age of children. They reported that the increase in childcare sensitivity was the highest during infancy to toddlerhood, but decreased as the children grew from toddlerhood to early childhood. Thus, it appears that interaction with children decreases to a certain degree, as mothers' childcare sensitivity decreases as their children grow. Especially in South Korea, children spend more time in childcare centers and interact more with teachers and siblings than with their mothers. Additionally, as mother-child interaction decreased most slowly over time when its initial value was higher, whereas the change in mother-child interaction was more rapid when the initial value was lower, and so the importance of promoting initial interaction along with implementing individual approaches to improving mother-child interaction was confirmed. In 2016, Chang et al..$^{27}$ conducted a family checkup intervention-a parent-child interaction promotion program. They reported that the program should be adopted when children are 2 to 5 years old to promote parent-child interaction. They added that such early adoption influences the effortful control of 5 -year-old children and influences the peer acceptance of 7.5 to 10 -year-old children. These findings emphasize that mother-child interaction is effective when early diagnosis and individualized long-term interventions are implemented. So, it is important to implement early intervention through appropriate diagnosis, especially for families experiencing mother-child interaction difficulty, and to provide continuous support to promote children's development and prevent future difficulty.

Second, the results of the multivariate latent growth model analysis showed that the initial value of motherchild interaction affected EF difficulty regardless of the level of maternal depression. This finding is similar to that of a previous study ${ }^{28}$ conducted with parents of infants, which reported that interactions between children and parents play a vital role in the development of EF abilities in children. Other studies ${ }^{14-17}$ on mothers with depression have also reported that mother-child interaction influences EF difficulty, which is similar to the findings of the present study. In light of the results of this and previous studies, the importance of early 
mother-child interaction for the improvement of children's EF is acknowledged and the need for a social support system is identified.

Third, the change rate of mother-child interaction significantly affected the children's EF difficulties in the normal-range maternal depression group, whereas the same was not observed in the mild or higher-level maternal depression group. This finding is different from those of previous studies, ${ }^{14-17}$ which reported that parent-child interaction negatively influenced children's EF when a parent had depression. As most studies are cross-sectional investigations centered on data obtained at one point, it is difficult to compare their findings with this study. Since the emotions of mothers whose depression level is within the normal range are stable, early mother-child interaction positively affects children even as time passes. As maternal depression levels do not change over a short period and children's perceptions of their mothers' depressive symptoms have long-term influences on their interactions, ${ }^{29}$ the latter is an important factor in the development of children's EF.

Fourth, the initial value of mother-child interaction and the value of the rate of change had a significant influence on children's school adaptation in the normalrange maternal depression group. However, the same was not observed in the mild or higher-level maternal depression group. Although it is necessary to pay attention to the former finding, the latter suggests that although the mother-child interaction does not directly influence children's school adaptation for mothers with mild or higher levels of depression, this influence is significant when EF is considered as a mediator. This finding appears to be related to the parenting attitude of mothers with mild or higher levels of depression. Previous studies have shown that mothers with depression use negative parenting behaviors due to their distorted perceptions of their children's behaviors caused by their negative emotions. Due to mothers' attitudes, such as negligence, blaming, and rejection, children have little opportunity to satisfy their need for affection, resulting in the reduction of positive mother-child interactions. ${ }^{4,30}$ Ultimately, this appears to affect children's development of EF, which negatively influences their school adaptation. Therefore, mother-child interaction education is necessary for mothers with mild or higher levels of depression, as it is, in turn, expected to positively influence children's EF. Most importantly, the improvement in children's EF promoted by increasing initial interaction with the mother may improve school adaptation automatically.

Fifth, the children's EF difficulties significantly influenced their school adaptation regardless of the maternal depression level. This finding agrees with many previous studies, ${ }^{3,5}$ which reported that EF is related to school adaptation and to various aspects of cognitive development in children and adolescents. EF is highly related to academic performance; achievements related to reading, mathematics, and science; and self-regulation related to learning and school life..$^{9,10}$ This study confirms that the EF difficulties of school-aged children negatively influence their school adaptation. Therefore, it is important to develop interventions by identifying the factors affecting children's EF. Related to this context, a previous study ${ }^{3}$ investigated EF and its change according to age showed that children's EF improves up to 15 years of age. However, since EF improvement slows down after that age after that, early involvement of parents and the society is important for preventing children's EF difficulties.

Suggestions for future research are as follows. First, an in-depth analysis on the direct and indirect influences of various variables affecting mother-child interaction, including maternal depression, is needed. Second, this study only investigated changes over three years using data from the 6th through 8th surveys of the Panel Study on Korean Children. As mother-child interaction is expected to vary when children reach adolescence, it is recommended that a comprehensive examination and in-depth analysis of the relationships and causality pertaining to changes in mother-child interaction and their influence on EF and school adaptation should be conducted by exploring data from more temporal points. Third, this study only examines the mother-child interaction relationship. Future research may confirm the research models of parent-child interaction by including fathers.

\section{Conclusions}

The significance of this study lies in its attention to the changing patterns of mother-child interactions, EF, and the trajectories of change in school adaptation from a longitudinal perspective using nationwide data rather than interpreting numerical values at a specific point. This study confirms its research models by dividing mother-child interaction into two groups based on the level of maternal depression (normal range and mild or higher-level depression). Furthermore, contrary to previous studies in which mothers have been included in a single group, the findings of this study can serve as basic data for providing individualized interventions for mother-child interaction in the future. Therefore, it is necessary to accurately evaluate the initial value of mother-child interaction and its changing patterns in the process of children becoming healthy adult members of society in order to identify people experiencing 
difficulties with mother-child interaction (such as mothers with depression), and to provide early interventions. Moreover, management and intervention for high-risk groups (as identified by testing for depression during prenatal tests) are necessary, and the programs delivered by trained experts that can regularly assess mother-child interaction and psychological state should be implemented. Developing and implementing intervention programs to improve mother-child interaction will positively influence children's school adaptation and improve their EF.

\section{References}

1. Akçinar B. The predictors of school adaptation in early childhood. Procedia Soc Behav Sci. 2013;93:1099-1104.

2. Cicchetti D. The organization and coherence of socioemotional, cognitive, and representational development: illustrations through a developmental psychopathology perspective on Down syndrome and child maltreatment. Nebraska Symp Motivation. 1988;36:259-366.

3. Best JR, Miller PH, Naglieri JA. Relations between executive function and academic achievement from ages 5 to 17 in a large, representative national sample. Learn Individ Differ. 2011;21:327-336.

4. Ashman SB, Dawson G, Panagiotides H. Trajectories of maternal depression over 7 years: relations with child psychophysiology and behavior and role of contextual risks. Dev Psychopathology. 2008;20:55-77.

5. Sosic-Vasic Z, Kröner J, Schneider S, Vasic N, Spitzer M, Streb J. The association between parenting behavior and executive functioning in children and young adolescents. Front Psychol. 2017;8:472.

6. Blair C, Ursache A. A Bidirectional Model of Executive Functions and Self-regulation. New York, NY: Guilford Press; 2011:300-320.

7. Baggetta P, Alexander PA. Conceptualization and operationalization of executive function. Mind Brain Educ. 2016;10:10-33.

8. Anderson PJ, Reidy N. Assessing executive function in preschoolers. Neuropsychol Rev. 2012;22:345-360.

9. Kaplan S, Berman M. Directed attention as a common resource for executive functioning and selfregulation. Perspect Psychol Sci. 2010;5:43-57.

10. Coghill DR, Hayward D, Rhodes SM, Grimmer C, Matthews K. A longitudinal examination

\section{Ethical approval}

Data were provided by the Panel Study on Korean Children after deliberation and the study was conducted after receiving a waiver for ethical approval (1040271201801-HR-001) from the Institutional Review Board (IRB) of Changwon National University.

\section{Conflicts of interest}

All contributing authors declare no conflicts of interest.

of neuropsychological and clinical functioning in boys with attention deficit hyperactivity disorder (ADHD): improvements in executive functioning do not explain clinical improvement. Psychol Med. 2014;44:1087-1099.

11. Glaser D. Child abuse and neglect and the brain - a review. J Child Psychol Psychiatry Allied Disciplines. 2000;41:97-116.

12. Caspi A, Moffitt TE, Morgan J, et al. Maternal expressed emotion predicts children's antisocial behavior problems: using monozygotic-twin differences to identify environmental effects on behavioral development. Dev Psychol. 2004;40:149-161.

13. Cipriano EA, Stifter CA. Predicting preschool effortful control from toddler temperament and parenting behavior. J Appl Dev Psychol. 2010;31: 221-230.

14. Comas M, Valentino K, Borkowski JG. Maternal depressive symptoms and child temperament: longitudinal associations with executive functioning. J Appl Dev Psychol. 2014;35:156-167.

15. Hughes C, Roman G, Hart MJ, Ensor R. Does maternal depression predict young children's executive function? - a 4-year longitudinal study. J Child Psychol Psychiatry Allied Disciplines. 2013;54: 169-177.

16. Pearson RM, Bornstein $\mathrm{MH}$, Cordero $\mathrm{M}$, et al. Maternal perinatal mental health and offspring academic achievement at age 16: the mediating role of childhood executive function. J Child Psychol Psychiatry Allied Disciplines. 2016;57:491-501.

17. Gueron-Sela N, Camerota M, Willoughby MT, Vernon-Feagans L, Cox MJ. Maternal depressive symptoms, mother-child interactions, and children's executive function. Dev Psychol. 2018;54:71-82.

18. Barnard KE. Nursing Child Assessment Satellite Training Learning Resource Manual. Seattle: 
University of Washington, School of Nursing; 1978:1-211.

19. McGrath JM, Records K, Rice M. Maternal depression and infant temperament characteristics. Infant Behav Dev. 2007;31:71-80.

20. Pawlby S, Sharp D, Hay D, O'Keane V. Postnatal depression and child outcome at 11 years: the importance of accurate diagnosis. J Affective Disord. 2008;107:241-245.

21. Min MH. Verification of a structural model of the relationship between family resources, parent-child interaction, academic skills, and school readiness of preschoolers. J Korea Open Assoc Early Child Educ. 2017;22:1-19: (in Korean).

22. Kessler RC, Andrews G, Colpe LJ, et al. Short screening scales to monitor population prevalences and trends in non-specific psychological distress. Psychol Med. 2002;32:959-976.

23. Song HJ. Validity of child-adolescent self-reported executive function difficulty screening questionnaire. Korean J Clin Psychol. 2014;33:121-137 (in Korean).

24. Chi SA, Jung DH. Validation of school adjustment inventory for first-grade elementary school students. Korean J Child Stud. 2006;27:1-15 (in Korean).

25. Kline RB. Principles and Practice of Structural Equation Modeling. New York: The Guilford Press; 2016:1-534.

26. Hallers-Haalboom ET, Groeneveld MG, van Berkel $\mathrm{SR}$, et al. Mothers' and fathers' sensitivity with their two children: a longitudinal study from infancy to early childhood. Dev Psychol. 2017;53:860-872.

27. Chang H, Shaw D, Shelleby E, Dishion T, Wilson $M$. The long-term effectiveness of the family checkup on peer preference: parent-child interaction and child effortful control as sequential mediators. J Abnorm Child Psychol. 2016;45:705-717.

28. Bernier A, Carlson SM, Whipple N. From external regulation to self-regulation: early parenting precursors of young children's executive functioning. Child Dev. 2010;81:326-339.

29. Beck CT. Postpartum depression: it isn't just the blues. Am J Nurs. 2006;106:40-50.

30. Attili G, Vermigli P, Roazzi A. Children's social competence, peer status, and the quality of mother-child and father-child relationships: a multidimensional scaling approach. Eur Psychol. 2010;15:23-33. 